\title{
A HOLISTIC LITERATURE REVIEW OF BUILDING INFORMATION MODELING FOR PREFABRICATED CONSTRUCTION
}

\author{
Shengxi ZHANG ${ }^{1}$, Zhongfu LI ${ }^{1}$, Tianxin $\mathrm{LI}^{1}$, Mengqi YUAN ${ }^{1,2^{*}}$ \\ ${ }^{1}$ Department of Construction Management, Dalian University of Technology, 116024 Dalian, China \\ ${ }^{2}$ Department of Architecture and Civil Engineering, City University of Hong Kong, 999077 Hong Kong, China
}

Received 6 December 2020; accepted 2 June 2021

\begin{abstract}
Building information modeling (BIM) and prefabricated construction (PC) are increasingly applied in the construction industry. Recent academic and industrial efforts indicated that the application of BIM and PC is a solution to reduce lifecycle costs, reduce waste, increase productivity and improve quality in construction. Although previous studies have advanced the integration of BIM and PC, extensive research scope and scattered research topics cannot form an overall picture of knowledge structure. Hence, this study aims to establish an up-to-date synthesis of the latest research on BIM for PC and identify the research gaps and future needs. First, a database with 103 journal articles on BIM for PC was established through data collection; second, a bibliometric analysis was applied to determine the top journals, articles and to map the latest mainstream research. Last, a qualitative analysis was used to determine the mainstream research areas and identify the research gaps and future needs. This study may contribute to enrich our body of knowledge on the use of the techniques in conjunction, help researchers and builders to understand the latest progress of BIM for PC research in timely fashion, and promote the integration of BIM with PC and other cutting-edge technologies moving forward.
\end{abstract}

Keywords: building information modeling (BIM), prefabricated construction (PC), literature review, bibliometric analysis, research gaps.

\section{Introduction}

The construction industry has been criticized for its low productivity, high lifecycle costs, and poor environmental performance (Abanda et al., 2017; Li et al., 2019a). These problems are mainly attributed to the lack of industrialization principles and poor information management in the past (Ezcan et al., 2013). Prefabricated construction (PC) and building information modeling (BIM) are recognized as feasible solutions to the crisis in the construction industry (Cabinet Office, 2011). As an off-site, factorybased production approach, PC incorporates the concepts of mass production and automation into construction to further streamline the process and increase worker productivity while enhancing eco-sustainability (Goodier \& Gibb, 2007; He et al., 2020). Featuring the product-oriented tasks and the wide geographical distribution of multistakeholders that form the temporary organization, a lack of communication between stakeholders has become the primary challenge for PC (Ezcan et al., 2013). Recently, emerging BIM technology has been recommended as the ideal technology to complement PC. Put simply, BIM is an object-oriented building information model, which contains the necessary data to plan certain phases of a building's life-cycle (e.g., scheduling, analyses, cost evaluation, etc.). Meanwhile, the industry defines BIM from a more macro perspective. According to the U.S. National BIM Standard, BIM is "a digital representation of the physical and functional characteristics of a facility", as well as "a shared knowledge resource for information about a facility that can form a reliable basis for decisions during its life-cycle, which is to say its existence from earliest conception to demolition" (National Building Information Model Standard Project Committee, 2018). Due to the model-centric and object-oriented core of BIM and the product-oriented characteristic of PC, the two technologies are highly complementary, and simultaneous application will maximize their benefits for the construction industry (Singh et al., 2019).

Despite the well-documented benefits, the widespread awareness and adoption of PC seems to be hindered (Nadim \& Goulding, 2011; Wuni \& Shen, 2020). The applica-

${ }^{*}$ Corresponding author. E-mail: mydlut7@163.com 
tion of PC technologies and practices of management remains at a low level (Li et al., 2016). Some studies attribute the deficiency to limited recognition of the benefits (Nadim \& Goulding, 2011), the lack of knowledge, experience and skill with the core concepts of the PC method (Goodier \& Gibb, 2007; Xue et al., 2018a), shipping limitations (O'Connor et al., 2016), lack of standardization (Ramaji \& Memari, 2018), the inability to execute early design freeze (Blismas et al., 2005), fragmentation and discontinuity of the entire prefabrication supply chain (Li et al., 2016), inefficient collaboration culture (Ramaji \& Memari, 2018), complex information and communication process (Nadim \& Goulding, 2011), ineffective communication among participants (Larsson et al., 2006), lack of platforms to increase interoperability and functionality (Annan et al., 2009), and that diverse multidisciplinary knowledge has yet to be integrated (Gao et al., 2018). To cope with the above issues, advanced technology and management techniques have been developed, such as Lean construction (Ballard et al., 2003), supply chain management (Wang et al., 2019), and BIM (Costa \& Madrazo, 2015).

Currently, the application of BIM for PC ("BIM for PC" is used to represent "the application of BIM for PC" hereafter) is attracting increased research attention, and several related recent studies have been devoted to analyzing how BIM can be used for PC, aiming to more fully explore the potential benefits of BIM for PC. These benefits include but are not limited to: greater precision in specifying material requirements (Abanda et al., 2017), better communication between stakeholders (Tang et al., 2019) and higher labor productivity (Poirier et al., 2015). To be exact, BIM provides digital representation of PC components and their rich geometric and semantic information, such as material composition, resource availability and manufacturing data, which can be used for simulating manufacturing strategies and determining a flexible production plan (He et al., 2020). Ezcan et al. (2013) investigated the interaction between BIM and PC, and indicated that using BIM with PC will increase the amount/scale of facilities that can be modeled while decreasing the modeling time and increasing quality (Ezcan et al., 2013). Several other studies investigated the advantages of BIM in promoting information management, especially the interoperability between PC components in terms of data sharing (Babič et al., 2010; Demian \& Walters, 2014; Li et al., 2019b). Furthermore, the "construction process simulation" and " $4 \mathrm{D}$ visualization of construction schedules" function of BIM is widely used for PC project management to perform logistic planning and control, planning resource utilization, and analyzing workspace congestion (Bortolini et al., 2019). Given the recent recognition of BIM and PC, some scholars have attempted to develop an effective platform to support information management and the decision-making process. For instance, an integrated conceptual framework was developed by combining the object-oriented attributes of $\mathrm{BIM}$ and the production-oriented characteristics of PC to support decision-making and collaboration in improving working efficiency (Li et al., 2019b).

In general, scholars have attempted to explore the application of BIM for PC from different perspectives, but the existing research trend is to focus on one topic in particular. The broad scope of research and disparate research topics cannot form an overall picture of knowledge structure. Although some recently published BIM for PC-related review articles were found (Abanda et al., 2017; Ezcan et al., 2013; Jin et al., 2018), they have some limitations. For instance, Jin et al. (2018) made a holistic review of the PC-related literature published between 2008 and 2018 and realized the potential of combining BIM and PC, but the study mainly focused on PC rather than BIM for PC specifically. Ezcan et al. (2013) and Abanda et al. (2017) qualitatively reviewed the research related to BIM for PC and proposed possible future opportunities with an emphasis on the technological potential of BIM for PC. However, these studies contained subjective speculation and a limited number of articles were selected, which may have produced biased results. A quantitative method may go a long way to bridge the research gap. In review, the existing literature review is insufficient, preventing researchers from the state-of-the-art development of BIM for PC based on both academic research and industrial practices.

To compensate for the deficiencies in the existing research, this study combines quantitative and qualitative methods in a holistic review of the literature on the research of BIM for PC by targeting the following objectives: to discover the most influential journals and top articles in this domain; to examine the latest mainstream research areas focus related to BIM for PC; to identify research gaps and propose research directions for future work on BIM for PC. The findings can help academic researchers and builders to understand the latest progress of BIM for PC research in a timely fashion, and promote the integration of BIM with PC and other cutting-edge technologies moving forward. To obtain a comprehensive review, the following three-step review approach was conducted: (1) collecting data utilizing appropriate keywords to select articles from Scopus; (2) determining the top journals, articles, and mapping the latest research through a bibliometric analysis and then highlighting the state-of-the-art of each area; and (3) determing the mainstream research areas and identifying the research gaps and future needs by qualitative analysis.

\section{Methods}

This study uses a holistic literature review to examine the latest mainstream research and identify gaps and future trends in the field of BIM for PC. Previous studies advocated this method in reviewing the literature, because it combines quantitative and qualitative methods for integration and analysis of available literature (Jin et al., 2018, 2019). The overall workflow is illustrated in Figure 1 and consists of three steps, namely, data collection, a bibliometric analysis, and quantitative analysis. 


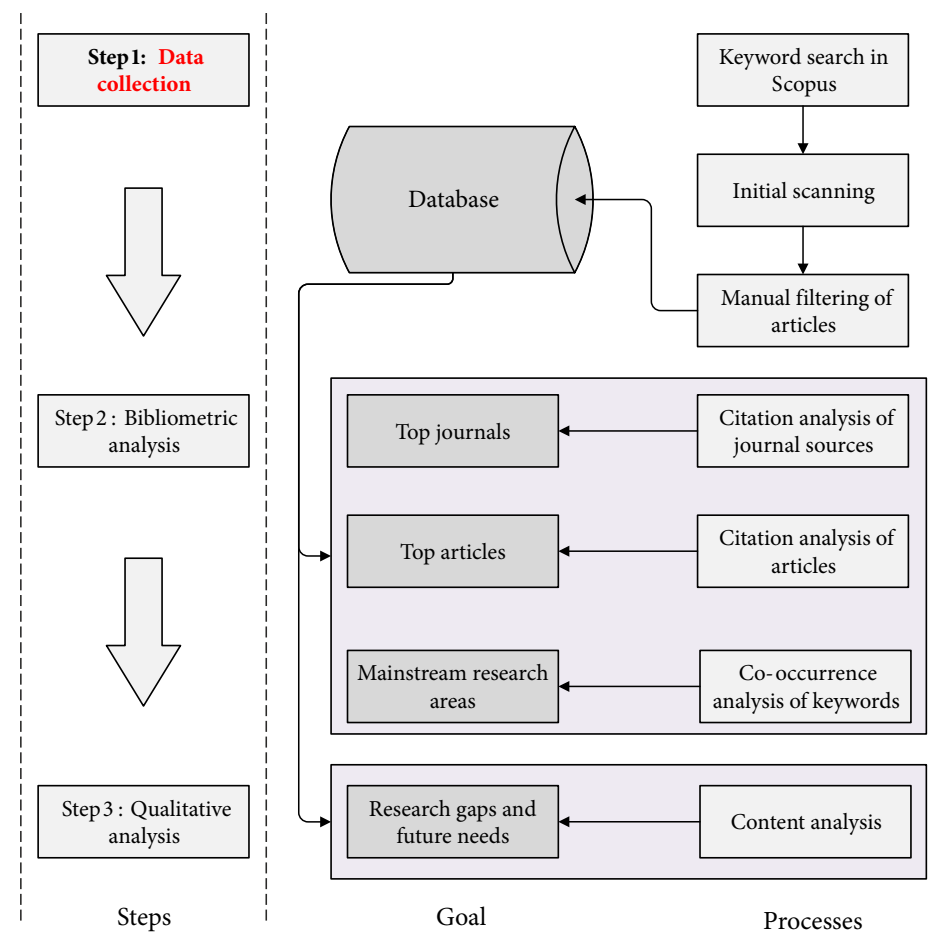

Figure 1. The three-step workflow of the literature review

\subsection{Data collection}

In this study, Scopus was selected as the database, because it covers a wider variety of journals and recent publications than other available databases (e.g., PubMed, Web of Science) (Meho \& Rogers, 2013). Data collection began with using appropriate keywords to search the title, abstract, and keyword sections of publications in the Scopus database. The search rule was:

TITLE-ABS-KEY (("building information model ${ }^{\star ”}$ OR "*BIM" OR "virtual design and construction" OR "VDC" OR "as-built model ${ }^{\star ”}$ OR "virtual model ${ }^{\star ”}$ OR “CAVT"*)

\section{AND}

("prefabrication" OR "prefabricated building" OR "prefabricated housing" OR "prefabricated construction" OR "precast concrete" OR "precast fabrication" OR "off* site construction" OR "off* site manufactur*" OR "off* site production" OR "modular construction" OR "modular building" OR "industriali?ed construction" OR "industriali?ed building*" OR "industriali?ed housing" OR "modern method $^{*}$ of construction")).

Notably, to obtain all valuable related publications, the search had no timeframe limitation.

Based on the aforementioned keywords, 370 journals were selected. However, some articles outside of the research scope were included in the search results. Thus, two additional criteria for article selection were employed to determine the research boundary.

(1) The papers selected for the study were all peerreviewed scientific journals in English to ensure the quality of the data. Conference papers were excluded because they are published with more frequency but less detail than journal papers (Jin et al., 2018).
(2) The focus of the selected articles was strictly limited to the application of BIM for PC. Articles beyond the scope of the Engineering, Construction and Architecture (ECA) industries were excluded.

Subsequently, each article in the search results was screened to exclude those that did not match all of the above criteria. Finally, a dataset of 103 articles was established for the present study.

\subsection{Bibliometric analysis}

A bibliometric analysis, is a quantitative method used for mapping the domain of scientific data on a given subject (van Eck \& Waltman, 2010), and has gained popularity among scholars of various disciplines (Oraee et al., 2017). Consequently, this paper adopts VOSviewer, a text-mining tool for bibliometric analysis that is available for free, to analyze and visualize the dataset in the domain of BIM for PC. The objectives of this step was to: 1) import the downloaded articles from Scopus; 2) visualize the distribution of articles according to year, journal title and citations contained, and analyze publication trends and the influence of key journals and articles; and 3) mapping the mainstream research areas based on co-occurrence of keywords analysis.

\subsection{Qualitative analysis}

Following the bibliometric analysis, a qualitative analysis was conducted to determine the mainstream areas and identify the potential research gaps and future needs. A qualitative method was chosen because it furnishes the broadest comparison of different studies and can help identify any blind spots in the existing research (Oraee 
et al., 2017). It should be noted that this method requires a detailed understanding of the content of each article. Although time-consuming, careful reading can help identify preliminary but significant research topics that are difficult to locate with a bibliometric analysis alone.

\section{Results}

\subsection{An overview of the literature sample}

After data collection, a database containing 103 journal articles was established in September 2020. The earliest article in the database was published in 2005 (Sacks et al., 2005). Sacks and Eastman, the authors of the article, are outstanding scholars in the BIM field. Figure 2 illustrates the distribution of the selected articles published yearly throughout the selected timespan. It reveals a pronounced upward trend in publications from 2005 to September 2020 , suggesting an increasing interest in the application of BIM for PC. Published research related to BIM for PC rapidly increased in 2015, and for the first time reached 10 papers per year. The current trend predicts that study in this field will continue to increase in the future.

\subsection{Citation analysis of journal sources}

The selected articles involve 36 journal sources. Identifying the key journals regarding BIM for PC can help readers to search for the highest quality articles (Hosseini et al., 2018). In the present study, the journal sources were analyzed using VOSviewer. The authors set the minimum number of documents (articles) and the minimum number of citations of a source at 1 and 30 , respectively. This threshold selection was based on two main reasons: (1) existing bibliometric literature review (Hosseini et al., 2018; Oraee et al., 2017); (2) multiple experiments to generate to create a readable and manageable network. In total, 18 out of 36 journals met al. conditions and were included in a network as shown in Figure 3. Each journal is represented by a node and a label. The number of articles published in each journal determines the size of the node. Most articles can be traced from their journal of origin to a larger body of research through the citations, represented by a path to a larger node. The connection lines indicate the direct citation between journals. The thicker the lines between two journals, the more mutual citations between them. The clusters of various colors represent the relatedness of journals in terms of direct citations. Note that some journals with low citations are not displayed in the figure, and some journal names may not be fully visible. Detailed information and quantitative measurements of the journals' influence are presented in Table 1. The main findings are summarized as follows.

As illustrated in Figure 3 and Table 1, Automation in Construction, with 28 articles and 1256 total citations, stands out as the most prominent journal in the field of BIM for PC. Journal of Cleaner Production (10 articles, 290 total citations), Journal of Computing in Civil Engineering (6 articles, 220 total citations) round out the top three journals in terms of the number of articles and total citations. The total link strength between them shows that the three journals also have the highest connection with other journals. However, some scholars believe that the quality of journals cannot be evaluated simply by the number of papers and the total citations. It is necessary to evaluate the average quality of the articles published in journals (Jin et al., 2018). Therefore, the average citations (Avg. citations) per article and the average normalized citations (Avg. norm. citations) are introduced. The Avg. citations and Avg. norm. citations were calculated according to Eqn (1) and Eqn (2):

$$
\begin{aligned}
& \text { Avg. citations }=\frac{\text { Total Citations }}{\text { Number of articles }} ; \\
& \text { Avg. norm. citations }=\frac{\text { Avg. citations }}{t},
\end{aligned}
$$

where $t$ denotes the average publication year of the articles published by a journal.

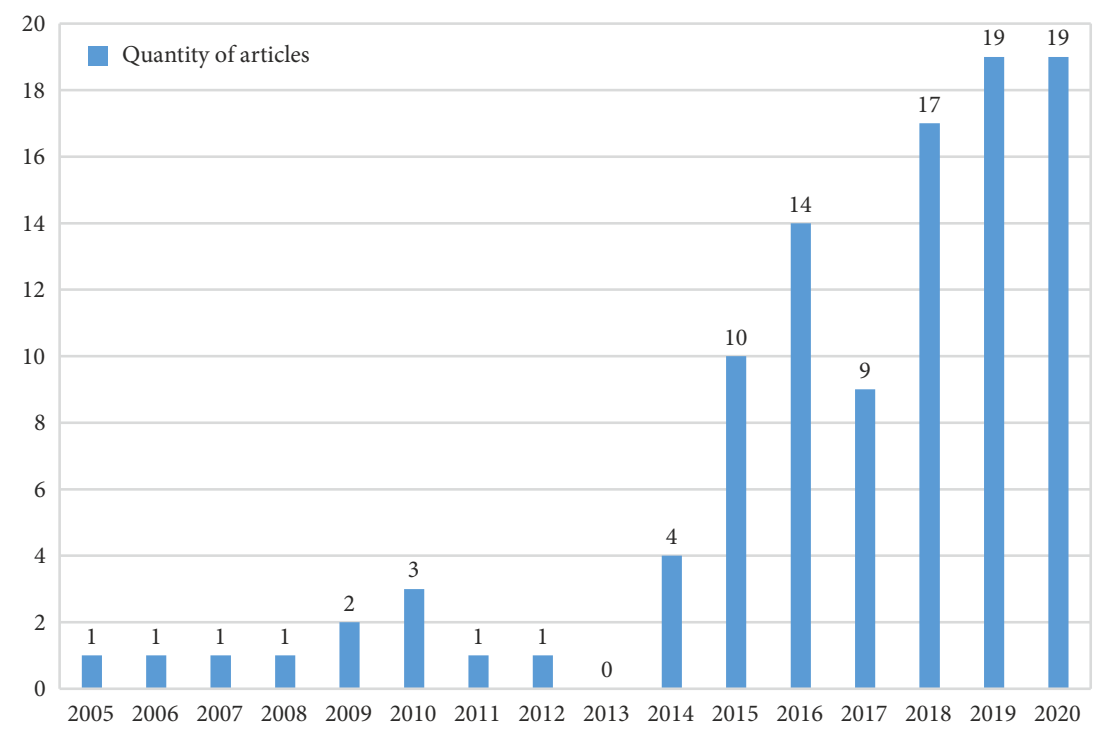

Figure 2. Distribution of published articles per year (2005-September 2020) 


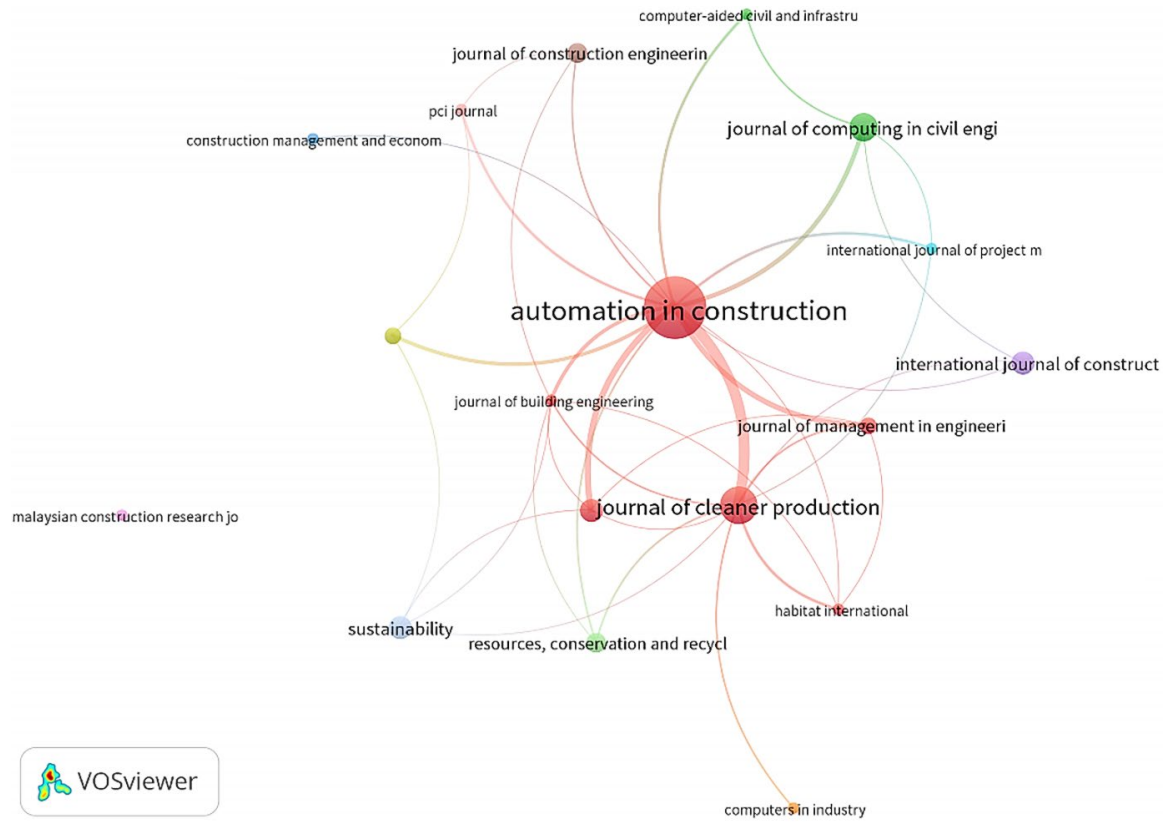

Figure 3. Mapping of influential journals in the research of BIM for PC

Table 1. Quantitative measurements of journals' influence

\begin{tabular}{|c|c|c|c|c|c|}
\hline Journal & $\begin{array}{l}\text { Number } \\
\text { of articles }\end{array}$ & $\begin{array}{l}\text { Total link } \\
\text { strength }\end{array}$ & $\begin{array}{c}\text { Total } \\
\text { Citations }\end{array}$ & $\begin{array}{c}\text { Avg. } \\
\text { citations }\end{array}$ & $\begin{array}{l}\text { Avg. norm. } \\
\text { citations }\end{array}$ \\
\hline Automation in Construction & 28 & 55 & 1256 & 45 & 1.25 \\
\hline Computer-Aided Civil and Infrastructure Engineering & 1 & 5 & 63 & 63 & 2.00 \\
\hline Computers in Industry & 1 & 2 & 37 & 37 & 1.04 \\
\hline Construction Management and Economics & 1 & 1 & 65 & 65 & 1.83 \\
\hline Electronic Journal of Information Technology in Construction & 2 & 6 & 79 & 40 & 0.60 \\
\hline Engineering, Construction and Architectural Management & 4 & 11 & 213 & 53 & 0.66 \\
\hline Habitat International & 1 & 6 & 45 & 45 & 1.42 \\
\hline International Journal of Construction Management & 4 & 3 & 32 & 8 & 2.83 \\
\hline International Journal of Project Management & 1 & 5 & 90 & 90 & 1.77 \\
\hline Journal of Building Engineering & 1 & 11 & 34 & 34 & 1.19 \\
\hline Journal of Cleaner Production & 10 & 28 & 290 & 29 & 1.58 \\
\hline Journal of Computing in Civil Engineering & 6 & 9 & 220 & 37 & 0.78 \\
\hline Journal of Construction Engineering and Management & 3 & 4 & 40 & 13 & 0.60 \\
\hline Journal of Management in Engineering & 2 & 10 & 30 & 15 & 0.72 \\
\hline Malaysian Construction Research Journal & 1 & 0 & 32 & 32 & 0.90 \\
\hline PCI Journal & 1 & 5 & 47 & 47 & 1.00 \\
\hline Resources, Conservation and Recycling & 3 & 5 & 197 & 66 & 1.72 \\
\hline Sustainability & 4 & 4 & 32 & 8 & 0.30 \\
\hline
\end{tabular}

In terms of Avg. citations per article, International Journal of Project Management, Resources, Conservation and Recycling, Construction Management and Economics, and Automation in Construction were shown to have a high influence. Owing to the fact that older articles have more time to be cited than recent ones, journals that have only made contributions to the field in recent years may be buried. The Avg. norm. citations reduce the impact of the time since publication and can be used to evaluate the contribution of the journal more accurately. The results indicate that International Journal of Construction Management, Computer-Aided Civil and Infrastructure Engineering, Construction Management and Economics, and International Journal of Project Management were shown to have a high influence per article per year. Besides, $A u$ tomation in Construction, Engineering, Construction and Architectural Management, Habitat International, Journal of Building, Journal of Cleaner Production, and Journal of Management in Engineering were categorized in the same cluster, indicating a high degree of interrelatedness. 
This is remarkable because these journals are not only deeply connected and reinforced by mutual citations, but also the top journals in the construction industry, which indicates that research of BIM for PC is a high priority for the construction industry.

\subsection{Citation analysis of top articles}

Citation information from the journal articles with the highest impact was extracted from VOSviewer. The 15 most cited articles in the database are listed in Table 2. Similar to the concept of the citation analysis used in Section 2.2, the measurement indicators of total citation and normalized citation were combined to analyze the articles to ensure objectivity in the citation analysis.

Lee et al. (2006) was the most cited study, which indicates that it is one of the earliest studies in the field of BIM for PC, and had a high impact on subsequent studies. Eastman et al. (2010) and Jeong et al. (2009) received the second and third highest citation numbers, respectively, but their normalized citation numbers were a little higher than Lee et al. (2006). These studies focus on the topics of information exchange and interoperability and made vital contributions to the application of BIM for PC. The outstanding scholars Eastman and Sacks contributed to all three studies. For all of the aforementioned reasons, this study ranks these as the top three articles. Although the study by Zhong et al. (2017), focusing on the integration of BIM with the Internet-of-Things (IoT), received the fourth-highest total citation number, it received the highest normalized citation. Two other articles, Li et al. (2018a) and Li et al. (2016), which have achieved higher standard citation rates, also developed the platform by integrating BIM and IoT to support decision making for PC. Therefore, it can be inferred that the IoT may be a high impact keyword in the field, which is verified in the next section. The study by Sacks et al. (2010) is strongly correlated with the top three studies, and also focused on the topics of information exchange and interoperability. Based on analysis from previous studies, Babič et al. (2010) and Chen et al. (2015) discussed the potential of BIM for PC and put forward a BIM-based implementation framework for PC. Kim et al. $(2015,2016)$ devoted themselves to the study of laser scanning for automatic quality inspection and their articles, Kim et al. (2015) and Kim et al. (2016) are cited in the top 15 most relevant articles. Akinade et al. (2015) and Ajayi et al. (2015) focused on how to reduce waste from PC projects to improve environmental sustainability, and they both received a high number of citations and standard citations. The last two studies, Kaner et al. (2008) and Demian and Walters (2014) focused primarily on defining the tangible benefits of BIM for PC and exploring potential applications.

Table 2. Top 15 articles with the highest impact in BIM for PC

\begin{tabular}{|c|c|c|c|}
\hline Author & Title & Citation & $\begin{array}{l}\text { Norm. } \\
\text { citation }\end{array}$ \\
\hline Lee et al. (2006) & $\begin{array}{l}\text { Specifying parametric building object behavior (BOB) for a building information modeling } \\
\text { system }\end{array}$ & 223 & 1.00 \\
\hline Eastman et al. (2010) & $\begin{array}{l}\text { Exchange model and exchange object concepts for implementation of national BIM } \\
\text { standards }\end{array}$ & 136 & 1.30 \\
\hline Jeong et al. (2009) & Benchmark tests for BIM data exchanges of precast concrete & 104 & 1.79 \\
\hline Zhong et al. (2017) & Prefabricated construction enabled by the Internet-of-Things & 98 & 3.42 \\
\hline Babič et al. (2010) & Integrating resource production and construction using BIM & 92 & 0.88 \\
\hline Chen et al. (2015) & Bridging BIM and building: from a literature review to an integrated conceptual framework & 90 & 1.77 \\
\hline Li et al. (2016) & $\begin{array}{l}\text { Schedule risks in prefabrication housing production in Hong Kong: a social network } \\
\text { analysis }\end{array}$ & 87 & 2.74 \\
\hline Kim et al. (2015) & $\begin{array}{l}\text { A framework for dimensional and surface quality assessment of precast concrete elements } \\
\text { using BIM and } 3 D \text { laser scanning }\end{array}$ & 86 & 1.70 \\
\hline Sacks et al. (2010) & $\begin{array}{l}\text { The rosewood experiment - building information modeling and interoperability for } \\
\text { architectural precast facades }\end{array}$ & 85 & 0.81 \\
\hline Akinade et al. (2015) & $\begin{array}{l}\text { Waste minimisation through deconstruction: a BIM based deconstructability assessment } \\
\text { score (BIM-DAS) }\end{array}$ & 74 & 1.45 \\
\hline Ajayi et al. (2015) & $\begin{array}{l}\text { Waste effectiveness of the construction industry: understanding the impediments and } \\
\text { requisites for improvements }\end{array}$ & 74 & 1.45 \\
\hline Kaner et al. (2008) & $\begin{array}{l}\text { Case studies of BIM adoption for precast concrete design by mid-sized structural } \\
\text { engineering firms }\end{array}$ & 67 & 1.00 \\
\hline $\begin{array}{l}\text { Demian and Walters } \\
\text { (2014) }\end{array}$ & The advantages of information management through building information modelling & 65 & 1.83 \\
\hline Li et al. (2018a) & $\begin{array}{l}\text { An internet of things-enabled BIM platform for on-site assembly services in prefabricated } \\
\text { construction }\end{array}$ & 64 & 2.96 \\
\hline Kim et al. (2016) & $\begin{array}{l}\text { Automated dimensional quality assurance of full-scale precast concrete elements using laser } \\
\text { scanning and BIM }\end{array}$ & 63 & 2.00 \\
\hline
\end{tabular}




\subsection{Co-occurrence of keywords}

To provide an accurate picture of the main research stream and topics covered in the domain of BIM for PC, a co-occurrence network of keywords was created using VOSviewer software. In the Scopus database, there are two types of keywords: (1) "author keywords", provided by authors, and (2) "index keywords", derived from the title and abstract of the article. The present study used both of the keywords extracted from the database containing 103 articles associated with BIM for PC. Notably, (1) some keywords with semantically consistent meaning were normalized, shown in Table 3, internet of things and internet of things (iot) were merged into "iot"; (2) general keywords, such as "BIM", "construction", "construction industry", were excluded because they do not add value to the present study. A total of 46 keywords connected by 351 links were selected. Figure 4 illustrates the keyword network, where the node size represents the frequency at which a keyword occurs, the line represents a link between two keywords, and the distance between two keywords indicates their relatedness. Moreover, the different colored nodes divide keywords into 6 clusters, which will be discussed later. Detailed quantitative information is presented in Table 3. Due to rapid innovation in the field, Table 3 contains as much information as possible for all keywords from Figure 4 to avoid overlooking newer topics.

As shown in Figure 4 and Table 4, except for PC, the top 5 items with the highest occurrence frequency were "Prefabricated components", "Decision making", "Design", "Information management", and "Project manage- ment". This reveals that the mainstream research on BIM for PC is from the perspective of using BIM technology to provide information management support for design, product management, and decision-making. The nodes of different colors categorize the keywords into 6 clusters. The keywords in each cluster are closely related, and usually, the keywords represent the primary content of existing research, so a cluster represents a mainstream area of research. The following section will determine the mainstream research areas by defining these clusters.

Table 3. Normalized keywords list

\begin{tabular}{|c|l|l|}
\hline No. & \multicolumn{1}{|c|}{ Original keywords } & \multicolumn{1}{c|}{ Normalized keywords } \\
\hline 1 & scanning & 3d laser scanning \\
\hline 2 & laser applications & 3d laser scanning \\
\hline 3 & components & prefabricated components \\
\hline 4 & precast concrete elements & prefabricated components \\
\hline 5 & sustainable development & sustainability \\
\hline 6 & internet of things & iot \\
\hline 7 & internet of things (iot) & iot \\
\hline 8 & building & buildings \\
\hline 9 & structural design & design \\
\hline 10 & architectural design & design \\
\hline 11 & $\begin{array}{l}\text { industry foundation } \\
\text { classes - ifc }\end{array}$ & ifc \\
\hline 12 & $\begin{array}{l}\text { radio frequency } \\
\text { identification (rfid) }\end{array}$ & rfid \\
\hline
\end{tabular}

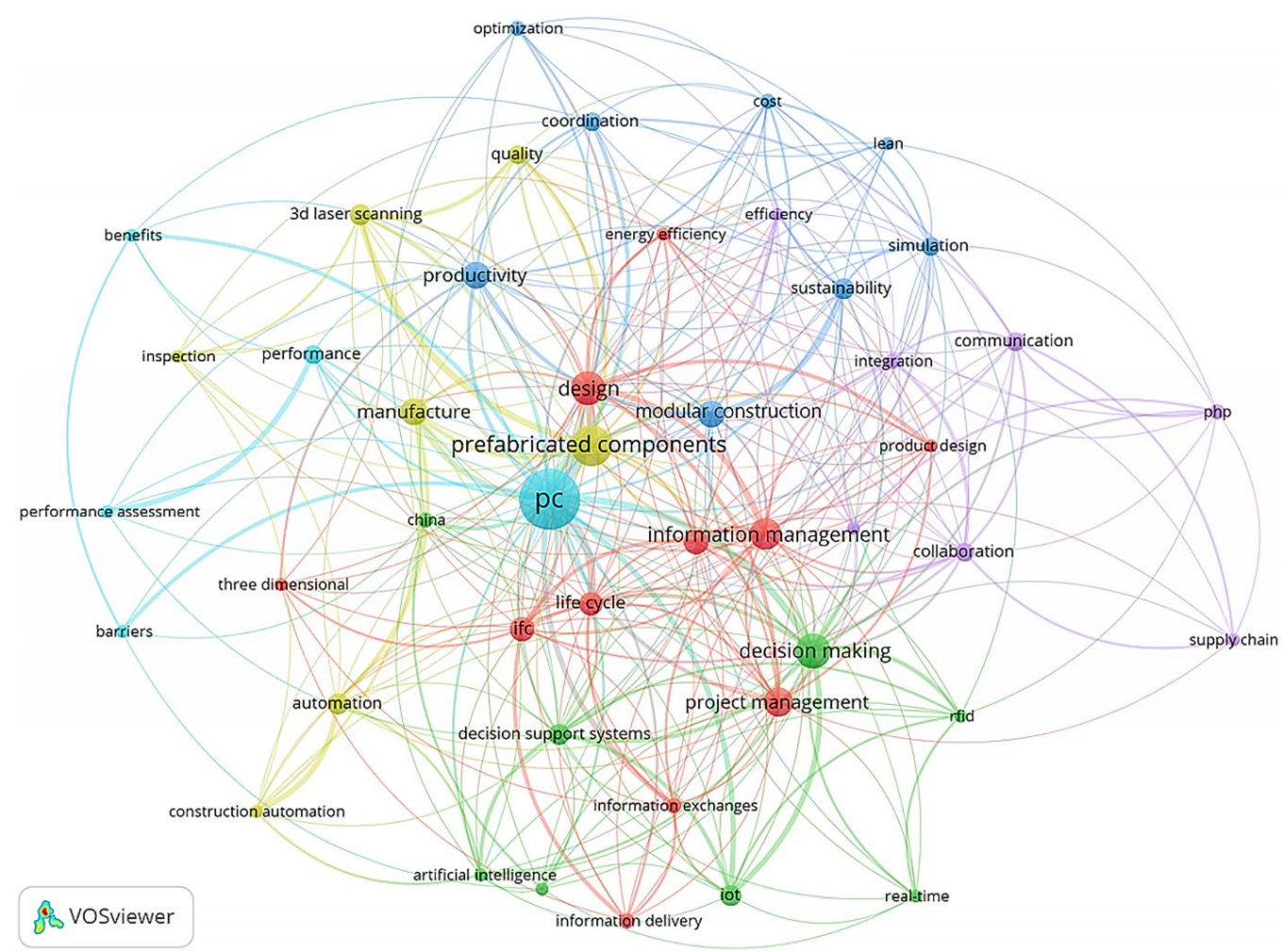

Figure 4. Mapping of co-occurrence keywords in the research of BIM for PC 
Table 4. Co-occurrence keywords in the articles of BIM for PC

\begin{tabular}{|c|c|c|c|c|c|}
\hline Label & $\begin{array}{l}\text { Total link } \\
\text { strength }\end{array}$ & Occurrence & Avg. pub. Year & Avg. citations & Avg. norm. citations \\
\hline $\mathrm{PC}$ & 95 & 28 & 2018 & 17.96 & 1.20 \\
\hline Prefabricated components & 49 & 17 & 2017 & 24.35 & 0.87 \\
\hline Decision making & 49 & 14 & 2018 & 29.57 & 1.40 \\
\hline Design & 47 & 13 & 2016 & 19.31 & 0.84 \\
\hline Information management & 39 & 12 & 2016 & 37.58 & 0.83 \\
\hline Project management & 32 & 11 & 2015 & 44.36 & 0.84 \\
\hline Manufacture & 27 & 10 & 2019 & 12.70 & 0.86 \\
\hline Modular construction & 32 & 10 & 2018 & 14.60 & 0.61 \\
\hline Productivity & 29 & 10 & 2015 & 30.40 & 0.65 \\
\hline IFC & 32 & 9 & 2016 & 49.67 & 1.13 \\
\hline Interoperability & 29 & 9 & 2014 & 64.11 & 1.41 \\
\hline Life cycle & 34 & 8 & 2019 & 11.50 & 0.96 \\
\hline 3D laser scanning & 23 & 7 & 2016 & 35.57 & 1.01 \\
\hline Automation & 19 & 7 & 2019 & 8.86 & 0.98 \\
\hline Sustainability & 21 & 7 & 2018 & 19.86 & 0.71 \\
\hline Decision support systems & 31 & 7 & 2018 & 45.29 & 1.77 \\
\hline IoT & 24 & 7 & 2018 & 37.71 & 2.04 \\
\hline Performance & 15 & 6 & 2017 & 34.33 & 1.00 \\
\hline Collaboration & 26 & 6 & 2018 & 15.00 & 1.08 \\
\hline Communication & 19 & 6 & 2018 & 39.50 & 1.73 \\
\hline Quality & 19 & 6 & 2017 & 21.67 & 0.72 \\
\hline Coordination & 16 & 6 & 2018 & 24.50 & 1.25 \\
\hline Simulation & 21 & 6 & 2016 & 51.17 & 0.85 \\
\hline Integration & 22 & 5 & 2017 & 14.00 & 0.89 \\
\hline PHP & 13 & 5 & 2018 & 29.80 & 1.45 \\
\hline Cost & 19 & 5 & 2017 & 13.40 & 0.50 \\
\hline Optimization & 11 & 5 & 2018 & 8.40 & 0.87 \\
\hline China & 15 & 5 & 2018 & 35.20 & 1.65 \\
\hline Information delivery & 14 & 5 & 2014.8 & 53.40 & 0.94 \\
\hline Information exchanges & 21 & 5 & 2016.4 & 36.20 & 0.62 \\
\hline Barriers & 8 & 4 & 2019 & 17.00 & 2.46 \\
\hline Benefits & 9 & 4 & 2018.5 & 14.75 & 1.86 \\
\hline Performance assessment & 9 & 4 & 2016.25 & 42.75 & 1.18 \\
\hline Conceptual frameworks & 16 & 4 & 2017 & 32.25 & 1.26 \\
\hline Efficiency & 20 & 4 & 2018.75 & 12.25 & 1.15 \\
\hline Supply chain & 9 & 4 & 2015.5 & 37.50 & 1.15 \\
\hline Construction automation & 14 & 4 & 2019.75 & 7.25 & 1.06 \\
\hline Inspection & 10 & 4 & 2018 & 31.50 & 1.26 \\
\hline Lean & 10 & 4 & 2017.75 & 28.50 & 1.49 \\
\hline Artificial intelligence & 20 & 4 & 2018.5 & 38.75 & 1.58 \\
\hline Hong Kong & 14 & 4 & 2016.5 & 53.50 & 1.55 \\
\hline Real-time & 12 & 4 & 2017 & 49.75 & 1.69 \\
\hline RFID & 16 & 4 & 2017.5 & 62.25 & 2.43 \\
\hline Energy efficiency & 17 & 4 & 2016.5 & 20.75 & 0.74 \\
\hline Product design & 16 & 4 & 2016.5 & 18.00 & 0.46 \\
\hline Three dimensional & 11 & 4 & 2009.75 & 82.75 & \\
\hline
\end{tabular}




\section{Qualitative analysis and discussion}

\subsection{Current research trend}

The keywords were categorized into intuitive clusters, which indicate the mainstream areas under the subject BIM for PC; however, the clusters are difficult to be defined and explained without a deep understanding of the literature's content. Therefore, on the basis of the co-occurrence network of keywords, we further read and compared the literature carefully and defined the 6 clusters in the present study as follows:

(1) Information exchange and interoperability (Red cluster)

Efficient information management is the key to PC success (Tang et al., 2019). The necessity of information management for PC has been emphasized extensively in previous studies (Ezcan et al., 2013; Turk, 2006). BIM is intended to increase data interoperability, information delivery quality and collaboration between stakeholders in construction projects (Ezcan et al., 2013). Consequently, some studies have been devoted to improving the information management capability of BIM for PC. The frequent keywords "IFC", "Information delivery", "Information exchanges", "Information management", and "Interoperability" in the cluster, and the close relationship between them, reflect the researchers' attention to these aspects. As early as 2005, Sacks et al. (2005) discussed the shared goal of integrating software applications used by different companies and to provide seamless data exchange between various participants in PC projects. Jeong et al. (2009) carried out a benchmark test of BIM data exchange for PC using a small but complex building model. The test results indicated that although the research and application of IFC have made significant progress, substantial efforts are necessary to achieve interoperability (Jeong et al., 2009). At present, BIM can provide communication and information exchange services for all participants through interoperable BIM components (Tang et al., 2019). IFC is an open standard data schema for data management and information exchange in the construction industry. To achieve interoperable digital exchange of product information in modular buildings, Ramaji and Memari (2018) defined new IFC concepts for representation of components and assemblies that are specific to modular buildings. Moreover, Eastman et al. (2010) outlined a precise procedure for developing information delivery manuals (IDM), which captures the use cases and the precise information to be exchanged (Eastman et al., 2010). Note that use of BIM is encouraged in the life cycle information management of PC to maximize the application benefits of BIM, however, the standard for the generation and exchange of data must be solved in the design stage, especially in parametric 3D modeling. Accordingly, we can see that "Design" and "Life cycle" also appear in this cluster and are closely linked with the other keywords.

(2) Decision support through integration of BIM with other innovations (Green cluster)

Previous studies highlighted that discontinuity of information is the key issue that hinders the intrinsically collaborative decision-making in PC projects ( $\mathrm{Li}$ et al., 2018b, 2019b). In recent years, some scholars have tried to overcome this difficulty by integrating BIM with other innovative technologies, such as RFID, Sensing, IoT, and Artificial Intelligence technologies (Chen et al., 2015; He et al., 2020; Li et al., 2019b). As stated by He et al., research needs to expand IoT and Artificial Intelligence to collect the many-layered data from PC progress, perform predictive analysis, and optimize the control decisions for the project operations (He et al., 2020). They developed a data-driven decision making system for the design and digital fabrication of PC by integrating these technologies with BIM. Li et al. (2018b) analyzed the importance of real-time data for managerial decision-making during component manufacture, transportation and on-site installation, and designed an IoT-based BIM platform ( $\mathrm{Li}$ et al., 2018b). The developed platform can provide a variety of decision support services to managers, for improving the efficiency of daily operations, decision making, collaboration, and real-time tracking. In their research, many advanced data acquisition, processing and tracking technologies were integrated into the platform, including RFID, virtual reality (VR) and IoT. Note that, China and Hong Kong (China) appear in this cluster. The two keywords not only appear over 10 times but also get a high score in average published citations and average normalized published citations. This indicates that scholars in these areas have made remarkable achievements. Related research, including but not limited to the above examples, has made great contributions to the study of BIM-based decision support tools for PC.

(3) BIM-based simulation and optimization to improve PC performance (Blue cluster)

Although previous studies have proclaimed tremendous advantages to the use of PC, scholars argue these advantages must be verified by quantitative methods (Wuni \& Shen, 2020), while PC processes must be optimized for productivity (Nath et al., 2015). As a digital facility that integrates construction-related quantitative data into a $3 \mathrm{D}$ model, BIM provides a virtual platform based on which many simulation and optimization works can be performed prior to the implementation of the construction of the physical facility (Hao et al., 2020). For example, the productivity of the manufacturing plan for prefabricated components was assessed by BIM-based $4 \mathrm{D}$ simulation technology (Lee \& Kim, 2017). Gbadamosi et al. (2019) developed a BIM-based assembly optimizer to improve PC productivity (Gbadamosi et al., 2019). Wang et al. (2018b) provided a 4D-BIM-based workspace modeling method for installation workspace analysis, which can promote the optimization of prefabricated components design. Interestingly, these studies on productivity improvement often suggest the adoption of Lean principles. Besides, BIM-based simulation related to cost also received considerable attention. For instance, Qi et al. (2018) developed a BIM-based incremental cost analysis model, which can greatly help investors to identify the most significant expenses and form effective cost optimization strategies. 
Further, the average published year of "sustainability" was 2018, shown in Table 4, which indicates BIM-based sustainability analysis is a more recent topic. Scholars believe that BIM offers an advanced tool for sustainability analysis in construction projects because of its advantages in visualization, coordination, simulation, and optimization (Hao et al., 2020). By analyzing carbon emission reduction during the materialization stage of a PC project, the BIM-based method proved to be efficient and capable of realizing significant emission reduction (Hao et al., 2020). To propose a comparative environmental analysis of conventional and prefabricated construction techniques, a BIM-based platform was used to measure relevant environmental merits and for supporting decision-making of appropriate construction techniques. Given that the above studies are enough to prove the potential of BIM-based analysis methods aiming to improve PC performance, the remaining studies will not be listed one by one. Future research should combine BIM with new technologies or optimization methods to further enhance the capability of BIM-based simulation and optimization.

(4) Laser scanning for automatic quality inspection (Yellow culster)

Prefabricated components are popular in PC projects, and there is increasing demand to ensure the dimensional quality of the components during the manufacturing (Kim et al., 2016). Currently, however, quality inspection is imprecise and time-consuming due to being operated manually (Wang et al., 2016). Scholars posit the need for vision-based sensors in quality inspection (Martinez et al., 2019), and an autonomous and intelligent quality inspection system is interoperable with BIM (Kim et al., 2015). Through the analysis of the co-occurrence keywords in Table 4, in conjunction with the content of the literature, reveals that some studies are trying to combine 3D laser scanning technologies with BIM for automatic quality inspection of prefabricated components (Guo et al., 2020; Martinez et al., 2019; Wang et al., 2018a). The 3D point cloud model of a prefabricated component with high precision, high density, fast speed, wide range and low sensitivity to light conditions can be obtained with $3 \mathrm{D}$ laser scanning (Guo et al., 2020). By comparing the 3D point cloud model with the pre-designed model, quality problems, such as deviations in dimensions (Kim et al., 2016), surfaces (Kim et al., 2015), and positions (Guo et al., 2020) can be detected. To leverage the potential of laser scanning in quality inspection and reduce manual operation, some studies try to integrate laser scanning technology with BIM to generate an as-built model automatically (Wang et al., 2018a). Furthermore, scholars have put forth a new algorithms which can ensure accuracy in quality detection and integrate it with BIM. For example, Xu et al. (2020) designed a more automated and more accurate quality control process by integrating the K-nearest neighbors $(\mathrm{KNN})$ algorithm with laser scanning and BIM. Current research focuses primarily on automatic quality inspection of small, prefabricated components under experimental conditions, further studies are needed to determine its feasibility with large-size prefabricated components.
(5) BIM-enabled collaboration and communication in PC projects (Purple cluster)

Previous studies highlighted the significance continuous collaboration among stakeholders in the construction process for the success of PC projects (Hu et al., 2019). BIM's capacity for seamless and timely information sharing and exchange between stakeholders has a significant impact on PC implementation (Ezcan et al., 2013; Mostafa et al., 2020), leveraging BIM capabilities may improve collaboration and communication between different stakeholders distributed throughout the PC supply chain. Hwang et al. investigated the significant constraints that demotivate the adoption of $\mathrm{PC}$, and proposed that the use of BIM to improve coordination and facilitate communication between project stakeholders is a key strategy to overcome the limitations (Hwang et al., 2018). Similar proposals have been proposed and validated by other scholars in the industry (Hwang et al., 2018; Tang et al., 2019). Furthermore, the BIM-based digital model/ concept framework was widely studied to integrate key stakeholders during the life cycle of a project (Chen et al., 2015; Zhai et al., 2019). For example, Abedi et al. (2016) developed a system architecture and prototype of Context-Aware Cloud Computing Building Information Modelling for effective communication and enhance collaboration among stakeholders in the supply chain. Nawi et al. (2014) proposed an integrated approach by combining BIM and Integrated Project Delivery (IPD) to ensure highly effective collaboration among stakeholders of PC. Many of the above studies mentioned the potential of BIM for stakeholder cooperation in PC projects. However, the literature focused on how BIM can facilitate the collaboration of stakeholders in PC projects, but limited systematic solutions were proposed.

(6) Drivers and barriers of BIM for PC (Pale blue cluster) As we have seen, the benefits of BIM can be applied to PC to help solve a variety of practical problems, such as how to achieve digital fabrication (He et al., 2020), transportation and storage tracking (Liu et al., 2020), as both academia and industry. The benefits have also been confirmed by some qualitative or quantitative studies. Ezcan et al. (2013) analyzed the challenges facing PC, and discussed how PC can benefit from BIM in order to enhance overall PC performance (Ezcan et al., 2013). This study illustrated that providing an improved design, facilitating organizational collaboration, and the storage and sharing of precise information are among the most evident benefits of BIM for PC. Tang et al. (2019) and Ji et al. (2019) used quantitative methods to study the impact of BIM benefits on PC performance (Ji et al., 2019; Tang et al., 2019). Improvements in environmental sustainability are being increasingly discussed. For example, waste of mulch material can be reduced with BIM-based prospective design and through the planning of the installation of roof coverings for PC buildings (Liu et al., 2019). Despite the benefits of BIM, the adoption of BIM for PC still faces challenges. Ji et al. (2019) summarized three main barriers: 1) existing business models are difficult to adapt to 
BIM applications; 2) many designers accustomed to CAD are not willing to change over to BIM, and 3) it is hard to change the existing pattern of cooperation and information sharing between the teams of different projects (Ji et al., 2019). Many other studies have found similar results, and meanwhile, further barriers have been identified, such as lack of BIM standards (Nawari, 2012), increased design cost (Tan et al., 2019), and the heterogeneity of the data involved (Rahimian et al., 2019). We also found that there are many investigations of the drivers of and barriers to BIM implementation, which do not distinguish between PC and traditional construction, but are highly relevant to the focus of this study.

In addition to the above 6 research topics determined by clustering, an unexpected result was obtained from Table 4 and Figure 4 . According to the average year of publication, "construction automation" received more attention around 2020, which indicates that the integration of BIM and PC to realize the automatic construction of PC is the latest research topic. However, through qualitative analysis of the literature, it can be found that most of the relevant research is focused on the manufacturing stage in the factory, and the "automation" related research is focused on laser scanning for automatic quality inspection. Although there are also researches on BIM-based automatic design (Alwisy et al., 2019; Liu et al., 2019), production (He et al., 2020), the numbers are very small and cannot cover the entire construction process. To be exact, existing research has not yet systematically investigated automated construction for PC, only the exploratory studies on the partial realization of automation. This means that automation construction is a goal worth striving toward, and may be a very hot research topic in the future.

\subsection{Research gaps and future needs}

Drawing upon the analysis of the current status of BIM for PC, several research topics and novel insights are summarized in the previous sections. On this basis, further qualitative analysis was presented to identify potential research gaps and future needs.

(1) Weaknesses in information exchange and interoperability among heterogeneous BIM applications cannot fully support PC. Research about information exchange and interoperability has made significant progress; however, we found that most of the relevant studies are based on specific cases, which leads to some discrepancies between research and application. According to Ramaji and Memari, existing information exchange standards cannot fully support PC (Ramaji \& Memari, 2018). PC project is essentially a temporary organization composed of relatively autonomous stakeholders (Xue et al., 2018b). Heterogeneous BIM applications may be adopted by different stakeholders within the same project. The data generated by one BIM application may be difficult to apply elsewhere, which means that the data cannot be effectively shared and processed. To support information exchange and interoperability of heterogeneous BIM applications in practice, BIM data requires many modifications which weakens the design benefit (Lu et al., 2017). According to a survey conducted by Tang et al., most of the PC projects involved in the survey use BIM for 3D modeling, but few projects can convert the information in a BIM model to other applications such as cost, schedule, or sustainability analysis (Tang et al., 2019). Therefore, improving the efficiency of information exchange and interoperability between heterogeneous BIM applications and applying the research results to practical projects need further research in the future.

(2) Research on the integration of BIM with other innovative technologies for PC is not adequately systematic. In recent years, many studies explored the possibility of integrating BIM with other new inventions to release the potential of BIM for PC. According to the aforementioned research areas in Section 3.1, existing studies mainly include data-driven decision-making and automated quality detection. These studies not only offer new perspectives in the area of BIM for PC, but also serve as a solid foundation for further research. However, they are experimental research under controlled conditions, which leaves them still a long way from developing practical applications. These studies mainly focus on the development of the functions related to cost, schedule, and quality management, without considering the management of safety, environmental and social impact. In addition, most research focuses on the component manufacturing stage and rarely involves the field assembly stage, while research covering the entire life cycle remains absent. Therefore, future research needs to be improved in light of existing results, try to develop more functions, cover more stages, and provide more systematic decision support and automated construction solutions for PC projects.

(3) Existing studies regarding BIM for PC seldom involve the Lean principle. Lean construction has already been widely adopted in PC projects (Ballard et al., 2003; Hosseini et al., 2018). Li et al. (2020) took Lean as one of the primary principles of industrialization. Scholars affirmed that Lean construction is an unavoidable topic in PC-related research (Li et al., 2019a). Moreover, the integration of Lean and BIM in construction has been widely discussed in previous studies (Sacks et al., 2010; Zhang et al., 2020), but according to the results in Figure 4 and Table 4, the keyword "Lean" is not prominent, very few studies have explored the integration of the BIM, PC and Lean. Li et al. (2018a) analyzed the interaction between BIM and the Lean principle, and developed a hands-on learning tool to simulate the PC process, from manufacturing and logistics to onsite assembly by integrating the BIM platform with Lean construction, as well as the training of students and practitioners. Nath et al. (2015) utilized the Lean principle to identify non-value adding activities in PC drawing design, and combined with BIM 
tools, proposed a simplified and coordinated design workflow. Bortolini et al. (2019) proposed the combined use of the Lean principle and BIM to cope with the complexity of site logistics planning and control of PC projects. Although these early studies explored the interaction and benefits of BIM and Lean in PC projects, they did not propose a systematic framework that integrates BIM with Lean for PC projects. Future research should explore and verify the feasibility of integrating BIM and Lean based on the requirements of PC projects and should propose a guiding implementation framework.

(4) Lack of research on organizational change adapted to the changing technological environment. Change is vital for organizations to remain competitive as new working paradigms and technology emerge (By, 2005; Erdogan et al., 2014). Wong et al. (2017) investigate the driving forces behind organizations adapting better uses of PC (Wong et al., 2017). Lindblad and Vass (2015) studied what changes organizations need to make with respect to BIM implementation. Almost all the studies mentioned that BIM can benefit from greater collaboration and communication among stakeholders. However, out of the 103 studies selected, few have analyzed the role and organizational relationship of stakeholders in the field of BIM for PC. Nevertheless, the significance of organizational change research can be found from 103 selected articles. For instance, in a study on the relationship between BIM implementation and PC project performance, cooperation of organizations was proven to have a dramatically positive effect on improving project performance (Tang et al., 2019). Nawi et al. (2014) proposed an integrated approach by combining BIM and IPD, and also explored a new organizational collaboration framework of BIM for PC. Yet, these studies need further investigation to refine a viable strategy for organizations to adapt and for stakeholders to play more useful roles.

(5) Few studies speculated on how to enhance the integration of BIM and PC through the improvement of PC technology. It is widely recognized that BIM can facilitate the delivery of PC projects (Tan et al., 2019). For that reason, numerous studies have been devoted to maximizing the benefit of BIM for PC (Ballard et al., 2003; Hosseini et al., 2018; Li et al., 2020; Ramaji \& Memari, 2018; Tang et al., 2019). However, the integration of BIM and PC not only requires improving BIM Technology, but PC technology as well. The fact is, PC is still in its infancy (Luo et al., 2015), its technological and managerial systems need to be further improved to better function in cooperation with BIM. For instance, the development of standardized and serialized prefabricated components could increase the amount/scale of facilities that can be modeled, while decreasing the modeling time and increasing the qual- ity. Standardized interface design could greatly reduce the in-depth design work of BIM technology. Innovative project delivery modes, such as IPD, can reduce the difference of BIM systems between different participants and improve the interoperability of data.

\section{Conclusions}

Due to the advantages of BIM and PC for reducing lifecycle costs, eliminating waste, increasing productivity, they are gaining increasing attention in both academia and industry. This study presented an in-depth review of the research on BIM for PC in pursuit of the state-of-the-art of this field. First, a total of 103 journal articles were selected to define the scope of the review through data collection. Then, a bibliometric analysis was performed to determine the top journals, articles and mapping the latest research areas. Lastly, the mainstream areas were defined and the research gaps and future needs were identified by qualitative analysis. The highlights of our findings are as follows:

- Since 2005, the research on BIM for PC has shown a pronounced increase, as does the higher number of publications on the subject in 2015. It is expected that studies in this field will continue to improve. The top journals and top articles were also presented herein.

- The latest mainstream areas were identified and divided into 6 categories: information exchange and interoperability, decision support by integration of BIM with other recent innovations, BIM-based simulation and optimization to improve PC performance, laser scanning for automatic quality inspection, BIM-enabled collaboration and communication in PC projects, drivers and barriers of BIM for PC.

- An in-depth quantitative analysis was carried out and identified 5 research gaps that need to be bridged in the future: Weaknesses in information exchange and interoperability among heterogeneous BIM applications cannot fully support PC; Research on the integration of BIM with other innovative technologies for PC is not adequately systematic; Existing studies regarding BIM for PC seldom involve the Lean principle; Lack of research on organizational change adapted to the changing technological environment; and few studies speculated on how to enhance the integration of BIM and PC through the improvement of PC technology.

This study can help academic researchers and the construction industry to understand the latest research on BIM for PC in a relatively short order, and promote the integration of BIM with PC and other advanced technologies. The limitation of this study is that to ensure the quality of selected articles, journal articles are used as the main source of the database, and some influential conference papers may have been ignored. Also, engineering practice issues are not included in this study, because the study focuses instead on the status of academic research. 


\section{Acknowledgements}

The authors appreciate the financial support of the National Natural Science Foundation of China [grant number 72071027].

\section{References}

Abanda, F. H., Tah, J. H. M., \& Cheung, F. K. T. (2017). BIM in off-site manufacturing for buildings. Journal of Building Engineering, 14, 89-102.

https://doi.org/10.1016/j.jobe.2017.10.002

Abedi, M., Fathi, M. S., Mirasa, A. K., \& Rawai, N. M. (2016). Integrated collaborative tools for precast supply chain management. Scientia Iranica, 23(2), 429-448. https://doi.org/10.24200/sci.2016.2129

Ajayi, S. O., Oyedele, L. O., Bilal, M., Akinade, O. O., Alaka, H. A., Owolabi, H. A., \& Kadiri, K. O. (2015). Waste effectiveness of the construction industry: Understanding the impediments and requisites for improvements. Resources, Conservation and Recycling, 102, 101-112.

https://doi.org/10.1016/j.resconrec.2015.06.001

Akinade, O. O., Oyedele, L. O., Bilal, M., Ajayi, S. O., Owolabi, H. A., Alaka, H. A., \& Bello, S. A. (2015). Waste minimisation through deconstruction: A BIM based Deconstructability Assessment Score (BIM-DAS). Resources, Conservation and Recycling, 105(Part A), 167-176.

https://doi.org/10.1016/j.resconrec.2015.10.018

Alwisy, A., Bu Hamdan, S., Barkokebas, B., Bouferguene, A., \& Al-Hussein, M. (2019). A BIM-based automation of design and drafting for manufacturing of wood panels for modular residential buildings. International Journal of Construction Management, 19(3), 187-205.

https://doi.org/10.1080/15623599.2017.1411458

Annan, C. D., Youssef, M. A., \& EI Naggar, M. H. (2009). Seismic overstrength in braced drames of modular steel buildings. Journal of Earthquake Engineering, 13(1), 1-21. https://doi.org/10.1080/13632460802212576

Babič, N. Č., Podbreznik, P., \& Rebolj, D. (2010). Integrating resource production and construction using BIM. Automation in Construction, 19(5), 539-543.

https://doi.org/10.1016/j.autcon.2009.11.005

Ballard, G., Harper, N., \& Zabelle, T. (2003). Learning to see work flow: an application of lean concepts to precast concrete fabrication. Engineering, Construction and Architectural Management, 10(1), 6-14.

https://doi.org/10.1108/09699980310466505

Blismas, N. G., Pendlebury, M., Gibb, A., \& Pasquire, C. (2005). Constraints to the use of Off-site production on construction projects. Architectural Engineering and Design Management, 1(3), 153-162. https://doi.org/10.1080/17452007.2005.9684590

Bortolini, R., Formoso, C. T., \& Viana, D. D. (2019). Site logistics planning and control for engineer-to-order prefabricated building systems using BIM 4D modeling. Automation in Construction, 98, 248-264. https://doi.org/10.1016/j.autcon.2018.11.031

By, R. T. (2005). Organisational change management: A critical review. Journal of Change Management, 5(4), 369-380. https://doi.org/10.1080/14697010500359250

Cabinet Office. (2011). Government construction strategy. http://www.cabinetoffice.gov.uk

Chen, K., Lu, W., Peng, Y., Rowlinson, S., \& Huang, G. Q. (2015). Bridging BIM and building: From a literature review to an integrated conceptual framework. International Journal of Project Management, 33(6), 1405-1416.

https://doi.org/10.1016/j.ijproman.2015.03.006

Costa, G., \& Madrazo, L. (2015). Connecting building component catalogues with BIM models using semantic technologies: An application for precast concrete components. Automation in Construction, 57, 239-248.

https://doi.org/10.1016/j.autcon.2015.05.007

Demian, P., \& Walters, D. (2014). The advantages of information management through building information modelling. Construction Management and Economics, 32(12), 1153-1165. https://doi.org/10.1080/01446193.2013.777754

Eastman, C. M., Jeong, Y.-S., Sacks, R., \& Kaner, I. (2010). Exchange model and exchange object concepts for implementation of national BIM standards. Journal of Computing in Civil Engineering, 24(1), 25-34.

https://doi.org/10.1061/(ASCE)0887-3801(2010)24:1(25)

Erdogan, B., Anumba, C. J., Asce, F., Bouchlaghem, D., \& Nielsen, Y. (2014). Collaboration environments for construction: Management of organizational changes. Journal of Management in Engineering, 30(3).

https://doi.org/10.1061/(ASCE)ME.1943-5479.0000231

Ezcan, V., Isikdag, U., \& Goulding, J. S. (2013, May 5-9). BIM and off-site manufacturing: Recent research and opportunities. In CIB World Building Congress, Construction and Society, Brisbane, Australia.

Gao, S., Low, S. P., \& Nair, K. (2018). Design for manufacturing and assembly (DfMA): a preliminary study of factors influencing its adoption in Singapore. Architectural Engineering and Design Management, 14(6), 440-456.

https://doi.org/10.1080/17452007.2018.1502653

Gbadamosi, A. Q., Mahamadu, A. M., Oyedele, L. O., Akinade, O. O., Manu, P., Mahdjoubi, L., \& Aigbavboa, C. (2019). Offsite construction: Developing a BIM-Based optimizer for assembly. Journal of Cleaner Production, 215, 1180-1190. https://doi. org/10.1016/j.jclepro.2019.01.113

Goodier, C., \& Gibb, A. (2007). Future opportunities for offsite in the UK. Construction Management and Economics, 25(6), 585-595. https://doi.org/10.1080/01446190601071821

Guo, J., Wang, Q., \& Park, J. H. (2020). Geometric quality inspection of prefabricated MEP modules with 3D laser scanning. Automation in Construction, 111, 103053.

https://doi.org/10.1016/j.autcon.2019.103053

Hao, J. L., Cheng, B., Lu, W., Xu, J., Wang, J., Bu, W., \& Guo, Z. (2020). Carbon emission reduction in prefabrication construction during materialization stage: A BIM-based life-cycle assessment approach. Science of the Total Environment, 723, 137870. https://doi.org/10.1016/j.scitotenv.2020.137870

He, R., Li, M., Gan, V. J. L., \& Ma, J. (2020). BIM-enabled computerized design and digital fabrication of industrialized buildings: A case study. Journal of Cleaner Production, 278, 123505. https://doi.org/10.1016/j.jclepro.2020.123505

Hosseini, M. R., Martek, I., Zavadskas, E. K., Aibinu, A. A., Arashpour, M., \& Chileshe, N. (2018). Critical evaluation of offsite construction research: A Scientometric analysis. Automation in Construction, 87, 235-247.

https://doi.org/10.1016/j.autcon.2017.12.002

Hu, X., Chong, H.-Y., Wang, X., \& London, K. (2019). Understanding stakeholders in off-site manufacturing: A literature review. Journal of Construction Engineering and Management, 145(8), 03119003.

https://doi.org/10.1061/(ASCE)CO.1943-7862.0001674 
Hwang, B. G., Shan, M., \& Looi, K. Y. (2018). Key constraints and mitigation strategies for prefabricated prefinished volumetric construction. Journal of Cleaner Production, 183, 183193. https://doi.org/10.1016/j.jclepro.2018.02.136

Jeong, Y. S., Eastman, C. M., Sacks, R., \& Kaner, I. (2009). Benchmark tests for BIM data exchanges of precast concrete. Automation in Construction, 18(4), 469-484.

https://doi.org/10.1016/j.autcon.2008.11.001

Ji, Y., Chang, S., Qi, Y., Li, Y., Li, H. X., Qi, K., \& Pellicer, E. (2019). A BIM-based study on the comprehensive benefit analysis for prefabricated building projects in China. Advances in Civil Engineering, Article ID 3720191. https://doi.org/10.1155/2019/3720191

Jin, R., Gao, S., Cheshmehzangi, A., \& Aboagye-Nimo, E. (2018). A holistic review of off-site construction literature published between 2008 and 2018. Journal of Cleaner Production, 202, 1202-1219. https://doi.org/10.1016/j.jclepro.2018.08.195

Jin, R., Yuan, H., \& Chen, Q. (2019). Science mapping approach to assisting the review of construction and demolition waste management research published between 2009 and 2018. Resources, Conservation and Recycling, 140, 175-188. https://doi.org/10.1016/j.resconrec.2018.09.029

Kaner, I., Sacks, R., Kassian, W., \& Quitt, T. (2008). Case studies of BIM adoption for precast concrete design by mid-sized structural engineering firms. ITcon, 13(Special issue Case studies of BIM use), 303-323.

Kim, M. K., Cheng, J. C. P., Sohn, H., \& Chang, C. C. (2015). A framework for dimensional and surface quality assessment of precast concrete elements using BIM and 3D laser scanning. Automation in Construction, 49, 225-238.

https://doi.org/10.1016/j.autcon.2014.07.010

Kim, M. K., Wang, Q., Park, J. W., Cheng, J. C. P., Sohn, H., \& Chang, C. C. (2016). Automated dimensional quality assurance of full-scale precast concrete elements using laser scanning and BIM. Automation in Construction, 72, 102-114. https://doi.org/10.1016/j.autcon.2016.08.035

Larsson, B., Sundqvist, J., Emmitt, S., Larsson, B., Sundqvist, J., \& Emmitt, S. (2006). Component manufacturers' perceptions of managing innovation. Building Research \& Information, 34(6), 37-41. https://doi.org/10.1080/09613210600822253

Lee, G., Sacks, R., \& Eastman, C. M. (2006). Specifying parametric building object behavior (BOB) for a building information modeling system. Automation in Construction, 15(6), 758-776. https://doi.org/10.1016/j.autcon.2005.09.009

Lee, J., \& Kim, J. (2017). BIM-based 4D simulation to improve module manufacturing productivity for sustainable building projects. Sustainability, 9(3), 426.

https://doi.org/10.3390/su9030426

Li, C. Z., Hong, J., Xue, F., Shen, G. Q., Xu, X., \& Luo, L. (2016). SWOT analysis and Internet of Things-enabled platform for prefabrication housing production in Hong Kong. Habitat International, 57, 74-87. https://doi.org/10.1016/j.habitatint.2016.07.002

Li, C. Z., Xue, F., Li, X., Hong, J., \& Shen, G. Q. (2018a). An Internet of Things-enabled BIM platform for on-site assembly services in prefabricated construction. Automation in Construction, $89,146-161$.

https://doi.org/10.1016/j.autcon.2018.01.001

Li, X., Shen, G. Q., Wu, P., Fan, H., Wu, H., \& Teng, Y. (2018b). RBL-PHP: Simulation of Lean construction and information technologies for prefabrication housing production. Journal of Management in Engineering, 34(2), 04017053. https://doi.org/10.1061/(ASCE)ME.1943-5479.0000577
Li, L., Li, Z., Li, X., \& Wu, G. (2019a). A review of global lean construction during the past two decades: analysis and visualization. Engineering, Construction and Architectural Management, 26(6), 1192-1216.

https://doi.org/10.1108/ECAM-03-2018-0133

Li, X., Shen, G. Q., Wu, P., \& Yue, T. (2019b). Integrating building information modeling and prefabrication housing production. Automation in Construction, 100, 46-60. https://doi.org/10.1016/j.autcon.2018.12.024

Li, L., Li, Z., Li, X., Zhang, S., \& Luo, X. (2020). A new framework of industrialized construction in China: Towards on-site industrialization. Journal of Cleaner Production, 244, 118469. https://doi.org/10.1016/j.jclepro.2019.118469

Lindblad, H., \& Vass, S. (2015). BIM implementation and organisational change: A case study of a large Swedish public client. Procedia Economics and Finance, 21(15), 178-184. https://doi.org/10.1016/S2212-5671(15)00165-3

Liu, H., Sydora, C., Altaf, M. S., Han, S., \& Al-Hussein, M. (2019). Towards sustainable construction: BIM-enabled design and planning of roof sheathing installation for prefabricated buildings. Journal of Cleaner Production, 235, 11891201. https://doi.org/10.1016/j.jclepro.2019.07.055

Liu, D., Li, X., Chen, J., \& Jin, R. (2020). Real-time optimization of precast concrete component transportation and storage. Advances in Civil Engineering, Article ID 5714910. https://doi.org/10.1155/2020/5714910

Lu, Y., Wu, Z., Chang, R., \& Li, Y. (2017). Building Information Modeling (BIM) for green buildings: A critical review and future directions. Automation in Construction, 83, 134-148. https://doi.org/10.1016/j.autcon.2017.08.024

Luo, L. Z., Mao, C., Shen, L. Y., \& Li, Z. D. (2015). Risk factors affecting practitioners' attitudes toward the implementation of an industrialized building system a case study from China. Engineering, Construction and Architectural Management, 22(6), 622-643. https://doi.org/10.1108/ECAM-04-2014-0048

Martinez, P., Ahmad, R., \& Al-Hussein, M. (2019). A visionbased system for pre-inspection of steel frame manufacturing. Automation in Construction, 97, 151-163. https://doi.org/10.1016/j.autcon.2018.10.021

Meho, L. I., \& Rogers, Y. (2013). Citation counting, citation ranking, and h-Index of human-computer interaction researchers: A comparison of Scopus and Web of Science. Journal of the American Society for Information Science and Technology, 64, 1852-1863.

Mostafa, S., Kim, K. P., Tam, V. W. Y., \& Rahnamayiezekavat, P. (2020). Exploring the status, benefits, barriers and opportunities of using BIM for advancing prefabrication practice. International Journal of Construction Management, 20(2), 146-156. https://doi.org/10.1080/15623599.2018.1484555

Nadim, W., \& Goulding, J. S. (2011). Offsite production: A model for building down barriers: A European construction industry perspective. Engineering, Construction and Architectural Management, 18(1), 82-101. https://doi.org/10.1108/09699981111098702

Nath, T., Attarzadeh, M., Tiong, R. L. K., Chidambaram, C., \& Yu, Z. (2015). Productivity improvement of precast shop drawings generation through BIM-based process re-engineering. Automation in Construction, 54, 54-68. https://doi.org/10.1016/j.autcon.2015.03.014

National Building Information Model Standard Project Committee. (2018). National BIM standard - United States.

Nawari, N. O. (2012). BIM standard in off-site construction. Journal of Architectural Engineering, 18(2), 107-113. https://doi.org/10.1061/(ASCE)AE.1943-5568.0000056 
Nawi, M. N. M., Haron, A. T., Hamid, Z. A., Kamar, K. A. M., \& Baharuddin, Y. (2014). Improving integrated practice through Building Information Modeling-Integrated Project Delivery (BIM-IPD) for Malaysian Industrialised Building System (IBS) construction projects. Malaysian Construction Research Journal, 15(2), 29-38. https://doi.org/10.1051/matecconf/20141501025

O'Connor, J. T., O'Brien, W. J., \& Choi, J. O. (2016). Industrial project execution planning: Modularization versus stick-built. Practice Periodical on Structural Design and Construction, 21(1), UNSP 04015014.

https://doi.org/10.1061/(ASCE)SC.1943-5576.0000270

Oraee, M., Hosseini, M. R., Papadonikolaki, E., Palliyaguru, R., \& Arashpour, M. (2017). Collaboration in BIM-based construction networks: A bibliometric-qualitative literature review. International Journal of Project Management, 35(7), 1288-1301. https://doi.org/10.1016/j.ijproman.2017.07.001

Poirier, E. A., Staub-French, S., \& Forgues, D. (2015). Measuring the impact of BIM on labor productivity in a small specialty contracting enterprise through action-research. Automation in Construction, 58, 74-84. https://doi.org/10.1016/j.autcon.2015.07.002

Rahimian, F. P., Chavdarova, V., Oliver, S., \& Chamo, F. (2019). OpenBIM-Tango integrated virtual showroom for offsite manufactured production of self-build housing. Automation in Construction, 102, 1-16.

https://doi.org/10.1016/j.autcon.2019.02.009

Qi, Y., Chang, S., Ji, Y., \& Qi, K. (2018). BIM-based incremental cost analysis method of prefabricated buildings in China. Sustainability, 10(11), 4293. https://doi.org/10.3390/su10114293

Ramaji, I. J., \& Memari, A. M. (2018). Extending the current model view definition standards to support multi-storey modular building projects. Architectural Engineering and Design Management, 14(1-2), 158-176.

https://doi.org/10.1080/17452007.2017.1386083

Sacks, R., Eastman, C. M., Lee, G., \& Orndorff, D. (2005). A target benchmark of the impact of three-dimensional parametric modeling in precast construction. PCI Journal, 50(4), 126-139. https://doi.org/10.15554/pcij.07012005.126.139

Sacks, R., Koskela, L., Dave, B. A., \& Owen, R. (2010). Interaction of Lean and Building information modeling in construction. Journal of Construction Engineering and Management, 136(9), 968-980.

https://doi.org/10.1061/(ASCE)CO.1943-7862.0000203

Singh, M. M., Sawhney, A., \& Borrmann, A. (2019). Integrating rules of modular coordination to improve model authoring in BIM. International Journal of Construction Management, 19(1), 15-31. https://doi.org/10.1080/15623599.2017.1358077

Tan, T., Chen, K., Xue, F., \& Lu, W. (2019). Barriers to Building Information Modeling (BIM) implementation in China's prefabricated construction: An interpretive structural modeling (ISM) approach. Journal of Cleaner Production, 219, 949-959. https://doi.org/10.1016/j.jclepro.2019.02.141

Tang, X., Chong, H.-Y., \& Zhang, W. (2019). Relationship between BIM implementation and performance of OSM projects. Journal of Management in Engineering, 35(5), 04019019. https://doi.org/10.1061/(ASCE)ME.1943-5479.0000704

Turk, Ž. (2006). Construction informatics: Definition and ontology. Advanced Engineering Informatics, 20(2), 187-199. https://doi.org/10.1016/j.aei.2005.10.002

van Eck, N. J., \& Waltman, L. (2010). Software survey: VOSviewer, a computer program for bibliometric mapping. Scientometrics, 84(2), 523-538.

https://doi.org/10.1007/s11192-009-0146-3
Wang, Q., Kim, M.-K., Cheng, J. C. P., \& Sohn, H. (2016). Automated quality assessment of precast concrete elements with geometry irregularities using terrestrial laser scanning. Automation in Construction, 68, 170-182.

https://doi.org/10.1016/j.autcon.2016.03.014

Wang, Q., Sohn, H., \& Cheng, J. C. P. (2018a). Automatic as-built BIM creation of precast concrete bridge deck panels using laser scan data. Journal of Computing in Civil Engineering, 32(3), 04018011. https://doi.org/10.1061/(ASCE)CP.1943-5487.0000754

Wang, Q., Guo, Z., Mei, T., Li, Q., \& Li, P. (2018b). Labor crew workspace analysis for prefabricated assemblies' installation: A 4D-BIM-based approach. Engineering, Construction and Architectural Management, 25(3), 374-411. https://doi.org/10.1108/ECAM-09-2016-0210

Wang, Z., Hu, H., Gong, J., Ma, X., \& Xiong, W. (2019). Precast supply chain management in off-site construction: A critical literature review. Journal of Cleaner Production, 232, 12041217. https://doi.org/10.1016/j.jclepro.2019.05.229

Wong, P. S. P., Zwar, C., \& Gharaie, E. (2017). Examining the drivers and states of organizational change for greater use of prefabrication in construction projects. Journal of Construction Engineering and Management, 143(7), 04017020. https://doi.org/10.1061/(ASCE)CO.1943-7862.0001309

Wuni, I. Y., \& Shen, G. Q. (2020). Barriers to the adoption of modular integrated construction: Systematic review and meta-analysis, integrated conceptual framework, and strategies. Journal of Cleaner Production, 249, 119347. https://doi.org/10.1016/j.jclepro.2019.119347

$\mathrm{Xu}, \mathrm{Z}$., Kang, R., \& Lu, R. (2020). 3D reconstruction and measurement of surface defects in prefabricated elements using point clouds. Journal of Computing in Civil Engineering, 34(5), 04020033. https://doi.org/10.1061/(ASCE)CP.1943-5487.0000920

Xue, H., Zhang, S., Su, Y., Wu, Z., \& Yang, R. J. (2018a). Effect of stakeholder collaborative management on off-site construction cost performance. Journal of Cleaner Production, 184, 490-502. https://doi.org/10.1016/j.jclepro.2018.02.258

Xue, X., Zhang, X., Wang, L., Skitmore, M., \& Wang, Q. (2018b). Analyzing collaborative relationships among industrialized construction technology innovation organizations: A combined SNA and SEM approach. Journal of Cleaner Production, 173, 265-277. https://doi.org/10.1016/j.jclepro.2017.01.009

Zhai, Y., Chen, K., Zhou, J. X., Cao, J., Lyu, Z., Jin, X., Shen, G. Q. P., Lu, W., \& Huang, G. Q. (2019). An Internet of Things-enabled BIM platform for modular integrated construction: A case study in Hong Kong. Advanced Engineering Informatics, 42, 100997. https://doi.org/10.1016/j.aei.2019.100997

Zhang, J., Li, H., Golizadeh, H., Zhao, C., Lyu, S., \& Jin, R. (2020). Reliability evaluation index for the integrated supply chain utilising BIM and lean approaches. Engineering, Construction and Architectural Management, 27(5), 997-1038. https://doi.org/10.1108/ECAM-12-2018-0542

Zhong, R. Y., Peng, Y., Xue, F., Fang, J., Zou, W., Luo, H., Ng, S. T., Lu, W., Shen, G. Q. P., \& Huang, G. Q. (2017). Prefabricated construction enabled by the Internet-of-Things. Automation in Construction, 76, 59-70.

https://doi.org/10.1016/j.autcon.2017.01.006 